\title{
NOVOS INSTITUTOS CONSENSUAIS DA AÇÃO ADMINISTRATIVA
}

\author{
Diogo DE FIGUEIREDO MOREIRA NETO
}

I- AS BASES; I - CONSENSO E CIVILIZAÇÃO - AS EXCELÊNCIAS DA AÇÃO CONSENSUAL NO DESENVOLVIMENTO DAS SOCIEDADES E A JUSTA MEDIDA DA COERÇÃO; 1.1 - O papel do consenso na evolução das culturas; 1.2 - O papel do consenso no desenvolvimento; 1.3 - O monopólio da coerção e o modelo de convivência que veio a caracterizar o Estado-Nação; 2 - UM PEQUENO HISTÓRICO DA ADMINISTRAÇÃO IMPERATIVA À ADMINISTRAÇÃO CONSENSUAL - A DEMOCRACIA CHEGA À ADMINISTRAÇÃO PÚBLICA: $1^{\circ}$ - OS DIREITOS FUNDAMENTAIS; $2^{\circ}$ - A SUBSIDIARIEDADE; $3^{\circ}$ - A PARTICIPAÇÃO E $4^{\circ}$ - A CONSTITUIÇÃO COMO NORMA; 2.1 - Surgimento do conceito liberal de função administrativa do Estado, ao lado das funções legislativa e judicial; 2.2 - Evolução assimétrica das três funções estatais, evidenciando a remanescência das caracerísticas autoritárias do "ancien régime" no ramo administrativo e o desequilíbrio nas relações sociedade e Estado; 2.3 - A recuperação dos valores humanísticos e liberais com o surto democrático iniciado no Segundo Pós-Guerra e os quatro vetores dessa mudança: $1^{\circ}$ - os direitos fundamentais; $2^{\circ}$ - a subsidiariedade; $3^{\circ}-a$ participação e $4^{\circ}$ a Constituição como norma; 2.4 - Os direitos fundamentais como fatores determinantes na promoção do reequilíbrio das relações entre sociedade e Estado na política e direito contemporâneos; $2.5-\mathrm{A}$ subsidiariedade e a redistribuição dos papéis do indivíduo, dos grupos sociais secundários e das instituiçôes políticas; $2.6-$ A participação se adensa em conseqüência das novas relações entre sociedade e Estado; 2.7 - A contribuição do conceito de Constituição como ordem de valores e a estrutura jurídica das novas relações entre sociedade e Estado; $3-A$ REDEFINIÇÃO TEÓRICA DO INTERESSE PÚBLICO NO ESTADO DEMOCRÁTICO DE DIREITO; 3.1 - O conceito de interesse público passa de obstáculo a aspecto essencial da administração pública por consenso; 
3.2 - Histórico da redefinição: o conceito de interesse público antes do estado de Direito, no Estado de Direito e no Estado Democrático de Direito. Graus de comprometimento da ação do Estado com a vontade da sociedade; 3.3 - O interesse público no constitucionalismo de resultado: da eficácia à efetividade; 3.4 - Reavaliação das relações sob os critérios postos pelos direitos fundamentais e pelos instrumentos da participação processualizada. Da relação de supremacia à relação de ponderação; $4-A$ PARTICIPAÇÃO PÚBLICA NO ESTADO DEMOCRÁTICO DE DIREITO: A EFICIÊNCIA COMO FIM E O PROCESSO COMO MEIO; 4.1 - Ainda a participação. Atuação impulsionadora da ação do Estado (escolha democrática de opções políticas) maximizadora da ação do Estado (exigência democrática finalística da eficiência); $4.2-$ A participação e a processualidade como seu inafastável instrumento democrático; II - ECLODE A ADMINISTRAÇÃO CONSENSUAL; 5 - EXPANSÃO DA ADMISSIBILIDADE DO CONSENSO NA ADMINISTRAÇÃO PÚBLICA - DAS MODALIDADES CONTRATUAIS ÀS NÄO-CONTRATUAIS; 5.1 - O consenso como instrumento de ação estatal. Uma classificação das modalidades pela natureza jurídica das prestações: o contrato e o acordo; 5.2 - A reduzida admissibilidade histórica do contrato e a expansão de sua admissibilidade como instrumento de ação administrativa pública; 5.3 - A expansão do pacto no Direito Administrativo contemporâneo com a admissão de vários tipos de acordo como modalidades não-contratuais; 6-OS TRE $S G \hat{E} N E$ ROS DA ADMINISTRAÇÃO PÚBLICA CONSENSUAL: A DECISÃO CONSENSUAL, A EXECUÇÃO CONSENSUAL E A SOLUÇÃO DE CONFLITOS CONSENSUAL; 6.1 - Uma classificação das modalidades consensuais da administração concertada segundo a natureza da função e o resultado administrativo visado, face aos interesses públicos a serem promovidos, satisfeitos ou recuperados; 6.2 - Intensidade da atuação consensual: o consenso como coadjuvante e como determinante da ação administrativa; III - GENEROS E ESPÉCIES DE ADMINISTRAÇÃO CONSENSUAL; 7 - O CONSENSO NA TOMADA DE DECISÃO ADMINISTRATIVA EXEMPLOS DE ESPÉCIES: PLEBISCITO, REFERENDO, A COLETA DE OPINIÃO, DEBATE PÚBLICO, AUDIÊNCIA PÚBLICA, ASSESSORIA EXTERNA, COGESTÃO E DELEGAÇÃO ATÍPICA; 7.I - O consenso como elemento coadjuvante da formação da vontade administrativa. Exemplos de espécies: coleta de opinião. debate público, audiência pública e assessoria externa: 7.2 - O consenso como elemento determinante da formação da vontade administrativa. Exemplos de espécies: plebiscito, referendo, audiência pública, cogestão e delegação atípica; 8 - O CONSENSO NA EXECUÇÃO ADMINISTRATIVA - EXEMPLOS DE ESPÉCIES: CONTRATOS ADMINISTRATIVOS DE PARCERIA E ACORDOS ADMINISTRATIVOS DE COORDENAÇÃO; 8.1 - A execução associada com sua caracerística sinérgico-sociopolítica de potenciar a capacidade de ação do Estado pela composição e pela soma de esforços; 8.2 - A execução associada por contrato e a sinergia da parceria. Espécies de contratos admi- 
nistrativos; 8.3 - A execução associada não-contratual por coordenação e sua sinergia. Modalidades: a cooperação e a colaboração. Execução mista: por cooperação e por colaboração. Exemplos de espécies de acordos administrativos: convênios, acordos de programa, "joint ventures" públicas $e$ conferências de serviços; 9 - O CONSENSO NA PREVENÇĀO DE CONFLITOS ADMINISTRATIVOS - EXEMPLOS DE ESPÉCIES: COMISSÕES DE CONFLITO E ACORDOS SUBSTITUTIVOS; 9.1 - A prevenção consensual de conflitos e suas caracteristicas e excelências sóciopolíticas. Extensibilidade das soluções; 9.2 - Espécies: as comissões de conflito e seu papel antecipatório e regulatório; os acordos substitutivos e sua natureza jurídica; 10 - O CONSENSO NA COMPOSIÇÃO DE CONFLITOS ADMINISTRATIVOS - EXEMPLOS DE ESPÉCIES: CONCILIAÇÃO, MEDIAÇÃO, ARBITRAGEM, AJUSTES DE CONDUTA E SIMILARES; 10.1 - A composição administrativa consensual de conflitos e suas características e excelências sócio-políticas. Extensibilidade das soluções; 10.2 - Espécies: a conciliação, a mediação, a arbitragem, os acordos substitutivos, os ajustes de conduta etc.; IV - CONCLUSÕES; $11-$ CONSENSUALIDADE ENQUANTO PRINCÍPIO E SUAS POSSIBILIDADES; 11.1 - A consensualidade enquanto princípio e sua inferência constitucional; 11.2 - Fomento público, subsidiariedade da coerção e a construção de um Estado de Justiça

\section{$I-A S B A S E S$}

1. Consenso e civilização - as excelências da ação consensual no desenvolvimento das sociedades e a justa medida da coerção

\subsection{O papel no consenso na evolução das culturas}

A determinação dos indivíduos, dos grupos sociais bem como a das nações, a que se agregam os respectivos meios de expressão - físicos e psíquicos - gera o poder de que dispõem para atingir a seus objetivos.'

É do emprego construtivo do poder em todos os seus níveis - pessoal e coletivos - que resulta a paulatina formação dos acervos de instituições que, em seu conjunto, conformam as várais culturas as quais, em certas circunstâncias, desabrocham em civilizaçōes.

1 O poder tem a antigüidade do homem e sempre exerceu fascínio, atração, assombro e medo, sendo, por isso, considerado, junto com o amor, por um de seus tratadistas clássicos, ADOLFO A. BERLE, "um dos mais velhos fenômenos das emoções humanas". (V. nosso Teoria do Poder, São Paulo, Revista dos Tribunais, 1992, p. 33). 
No processo formador de culturas e de civilizações, o dinamismo do poder comporta dois tipos de relações cratológicas: a cooperação e o antagonismo.

$\mathrm{O}$ antagonismo, que leva aos confrontos de poder, aos conflitos e às guerras, tem na competição a mola do progresso, mas é uma forma eticamente pobre, pois não raras vezes cobra um alto preço em vida e valores humanos. Por isso, desenvolveram-se imemorialmente instituições destinadas a realizar a prevenção e a composição dos conflitos, para que deles se pudesse retirar os benefícios da competição sadia, ou seja, minimizando a agonal e maximizando o arquitetônico.

Mas, por outro lado, está na cooperação o tipo de relacionamento que possibilita a coordenação de diversas expressões de poder para o atingimento de fins comuns, desenvolvendo virtudes sociais como a tolerância e a confiança, possibilitando a concertação de vontades e o surgimento do consenso: o tema central deste ensaio. 2

\subsection{O papel do consenso no desenvolvimento}

A moderna literatura sociopolítica sobreleva o papel das instituições do consenso na construção de sociedades livres, em substituição aos sistemas que se fundavam fortemente nas instituições de comando.

É certo que a coerção é imprescindível para a existência das sociedades humanas mas também é certo de que não é suficiente para que elas progridam livremente, de modo a permitir o pleno desenvolvimento das potencialidades individuais.

Por outro lado, a desconfiança, que leva à divergência, porque deriva do instinto de sobrevivência, é inata, ao passo que a confiança, que conduz à convergência, surge no plano da consciência e exige um nível de refinamento cultural na medida em que as instituições vão criando fatores comportamentais que atuem reduzindo as inibições e, ao revés, promovam a ativação de uma etologia do desenvolvimento. ${ }^{3}$

Em resumo, essa hipótese de trabalho se assenta na idéia de que o desenvolvimento sustentado de povos e de civilizações "reside na confiança acordada à iniciativa pessoal, à liberdade explorativa e inventiva", embora reconhecendo a contrapartida de limites e de deveres. ${ }^{4}$

\subsection{O monopólio da coerção e o modelo de convivência que veio a caracterizar o Estado-Nação}

Os modelos políticos antigos raramente abriam espaços a essa fundamental e necessária liberdade individual e, por isso, não eram propícios à formação de pólos

2 Consenso, no sentido psicológico, é a coincidência de sentimentos; no sentido sociológico é a coincidência de propósitos e no sentido jurídico, que lhe confere DE PLÁCIDO E SILVA, é a coincidência na "manifestação de vontade" (Vocabulário Jurídico, Rio de Janeiro, Forense, 1989, Vol. II, p. 520).

3 Acompanha-se, quanto à etologia comparada do desenvolvimento, as lições de ALAIN PEYREFITTE em sua vigorosa contribuição à sociologia do desenvolvimento: La Societé de Confiance, Paris, Éditions Odile Jacob, Paris, 1995, especialmente ps. 11 a 23.

4 Obra supracitada, p. 15. 
de consenso na sociedade; ao contrário, fundavam-se na concepção oposta, de que era necessária a existência de um pólo de poder dotado de suficiente concentração de poder para impor comportamentos e assegurar uma convergência fundada na coerção.

Ainda assim. foram esses modelos antigos que serviram de base para a criação do modelo renascentista do Estado-Nação, que até hoje, embora com muitas alterações, é o que se perpetua na organização política dos povos, mantendo-lhe as características de imperatividade. Como sua orientação germinal não foi a busca do consenso, mas a imposição da coerção, explica-se a multicentenária evolução desse modelo, passando pela importante mudança novecentista do Estado de Direito, de corte iluminista, para chegar, na segunda metade do século passado, ao Estado Democrático de Direito, nele já se podendo distinguir, dentre sua plêiade de princípios de inspiração libertária, um princípio do consenso em construção, que pode ser sumariamente definido como o primado da concertação sobre a imposição nas relações de poder entre a sociedade e o Estado.

Inaugura-se, assim, uma era de relações paritárias entre esses dois protagonistas da cena política, mas precisamente entre os cidadãos e a Administração, como a seguir se desenvolve.

2. Um pequeno histórico da administração imperativa à administração consensual - a democracia chega à administração pública: $1^{\circ}$ - os direitos fundamentais; $2^{\circ}$ - a subsidiariedade; $3^{\circ}$ - a participação e $4^{\circ}-a$ constituição como norma

\subsection{Surgimento do conceito liberal de função administrativa do Estado, ao lado das funções legislativa e judicial}

A desagregação do exercício do poder estatal concentrado no soberano, que produziu originariamente três complexos de funções autonômicas, desde então designadas como "poderes", por metonímia, foi uma auspiciosa dádiva das três revoluções liberais: a inglesa, que firmou a instituição parlamentar como sede autônoma do exercício da função legislativa; a americana, que criou um sistema judiciário com garantia de autonomia para o exercício da função judicial; e a francesa, que transferiu do rei a uma burocracia autônoma o exercício da função administrativa.

\subsection{Evolução assimétrica das três funções estatais, evidenciando-se a remanescência das caracteristicas autoritárias do "ancien régime" no ramo administrativo e o desequilíbrio nas relações sociedade e Estado}

Mas, enquanto, a partir do legado inglês, a evolução da função legislativa e a da função judicial assinalavam uma crescente harmonização entre a sociedade e o Estado, pavimentando nos últimos duzentos anos o desenvolvimento de uma sólida teoria de direitos fundamentais e do primado da cidadania, de modo discrepante, a 
função administrativa ainda manteria, durante muito tempo a postura imperativa herdada dos tempos do absolutismo, mostrando-se impérvia 'absorção de valores liberais e democráticos, só cedendo no curso do século vinte, graças à evolução metodológia do Direito e do Direito Administrativo em particular. ${ }^{5}$

Assim é que coube ao Direito Administrativo tradicional suprir com uma brilhante elaboração doutrinária e jurisprudencial esse déficit liberal e democrático dos sistemas políticos do Estado de Direito. restabelecendo o equilíbrio real entre as três funções tradicionais e seis respectivos complexos orgânicos, os assim chamados três poderes do Estado e, mais do que isso, buscando a paridade das relações entre o Estado-administrador e o cidadão-administrado.

A abertura proporcionada, desbastando o poder de império que havia ficado concentrado no ramo executivo do Estado, possibilitou, entre outros aperfeiçoamentos, o exame do mérito do ato administrativo, imprescindível para o controle do correto exercício da discricionariedade: a processualização da ação administrativa, em benefício da segurança das relações entre as entes públicos e privados; e a desmitificação do conceito positivista de interesse público, até há pouco formulado em tese em termos absolutos, para que se considerassem, em cada hipótese, a concorrência de outros valores, iguais ou supraordinados, em termos de ponderação.

\subsection{A recupeação dos valores humanísticos e liberais com o surto democrático iniciado no Segundo Pós-Guerra e os quatro vetores dessa mudança: $1^{\circ}$ - os direitos fundamentais; $2^{\circ}-$ a subsidiariedade: $3^{\circ}-$ a participação e $4^{\circ}-a$ Constituição como norma}

Foi, contudo, sob o influxo dos dramáticos acontecimentos que marcaram a Segunda Guerra Mundial e das conquistas prodigalizadas pela Revolução das Comunicações, que a sociedade se mobilizou para varrer definitivamente os restolhos do antigo regime, que até então parecia ter apenas substituído o poder do rei pelo poder absoluto do Estado, mantendo o imenso distanciamento da sociedade que caracterizava a relação com súditos.

Esse súdito, com a ressurreição democrática do Segundo Pós-Guerra, logo transformar-se-ia em cidadão, dando-se a recuperação dos valores liberais dormitantes e dos valores democráticos substantivos; encerrava-se um periodo em que tanto o liberalismo quanto a democracia estavam limitados e comprometidos pelo decisionismo político e pelo formalismo jurídico.

Com as novas democracias, emergentes da catástrofe bélica, afirmavam-se quatro vetores principiológicos: os direitos fundamentais, a subsidiariedade, a participação e a Constituição como ordem de valores.

5 Entre outras contribuições críticas sobre so aspectos aqui tratados, vale consultar o trabalho de JOSÉ EUGENIO SORIANO GARCÍA, Desregulación, Privatización y Derecho Administrativo, Bolonha, Publicação do Real Colégio de Espanha, 1993, especialmente seu Capítulo 2, sob o título: Los fundamentos históricos del Derecho Administrativo: la Revolución Francesa y sus consecuencias para nuestra disciplina. 
2.4. Os direitos fundamentais como fatores determinantes na promoção do reequilibrio das relações entre sociedade e Estado na política e direito contemporâneos

A inspiração libertária dos direitos fundamentais, à feição francesa, surgida no século XVIII como reação à concentração do poder real, embora importante, foi insuficiente para servir de base às novas relações entre sociedades abertas e democráticas e Estados igualmente abertos e limitados, não apenas pela legalidade como também pela legitimdiade e pela licitude no emprego do poder.

A inspiração igualitária, que tanto enriqueceria o rol dos direitos fundamentais no Estado Democrático de Direito, também ficaria muito a dever, como hoje é reconhecido, ao trabalho de grandes juristas, que pavimentaram com valores permanentes e universais os sendeiros que seguiriam os Direitos de seus respectivos países. ${ }^{6}$

\subsection{A subsidiariedade e a redistribuição dos papéis do indivíduo, dos grupos sociais secundários e das instituições políticas}

Este segundo vetor, dos quatro destacados, atua como reorganizador não apenas das relações aqui tratadas, entre sociedade e Estado, como de todas as relações internas entre entidades e órgãos que dele se vão desdobrando em um processo contínuo de desmonopolização do poder. Com a subsidiariedade ocorre, assim, uma nova e mais dinâmica aplicação do luminoso princípio da separação de poderes, hoje, mais apropriadamente, relido como separação de funções autônomas.

Em síntese, atende-se ao princípio da subsidiariedade sempre que a decisão do poder público venha a ser tomada da forma mais próxima possível dos cidadãos a que se destinem. ${ }^{7}$ Tal proximidade visa a garantir que o órgão administrativo considerará sempre em suas decisões: primeiro, que sejam respeitados os direitos e iniciativas dos cidadãos e das entidades privadas; segundo, que qualquer intervenção administrativa só se produza em caso de inexistência ou insuficiência da iniciativa

6 Vale transcrever aqui. do administrativista maior da latinidade, EDUARDO GARCÍA DE ENTERRÍA, e de TOMÁS RAMÓN FERNÁNDEZ, as palavras com que resumem a importância da contribuição do direito dos juristas, mesmo enfrentando tempos politicamente difíceis e os encastelamentos dos radicalismos ideológicos:

"Es un hecho... que las obras clásicas de los grandes juristas mantienen un valor permanente, por encima de los cambios legislativos, incluso, aún más, por encima de los respectivos derechos nacionales; lo cual no es sino una consecuencia de que esas obras alumbran o explicilan principios institucionales permanentes, no caducables con el cambio de las normas escritas que ocasionalmente los reflejan. directamente o aún por vía de contraste y oposición". (Curso de Derecho Administrativo, Madri, Vol. I, 5 a edição, p. 75 - nosso destaque em negrito).

7 Cf. as Conclusóes do Conselho Europeu de Edimburgo, de 12 de dezembro de 1992. referidas ao Princípio de Subsidiariedade: enfoque geral de aplicação, pelo referido Conselho, deste princípio e do Art. $3^{\circ}$ do Tratado da União Européia (Gazeta Jurídica de la CEE, B-81, janeiro/fevereiro de 1993, p. 63). 
individual ou social; terceiro, que neste caso, a intervenção só se dará na medida indispensável para atender ao interesse público legal e legitimamente definido; e, quarto, que outros entes ou órgãos administrativos menores não tenham condições de agir com eficiência.

Assim, nas atuais sociedades humanas, que deixaram de ser uniclasse e monolíticas ou divididas em duas ou poucas classes sociais e com quase nenhuma mobilidade interna, como no passado, para se tornarem sociedades pluriclasse e de alta mobilidade, somente a aplicação desse princípio pode proporcionar as condições para um atendimento diversificado e, por isso mesmo, adequado, das plúrimas necessidades que demandam satisfação coletiva pelos meios atribuídos ao Estado.

\subsection{A participação se adensa em conseqüiência das novas relações entre sociedade e Estado}

A efetiva aplicação dos dois vetores tratados - o dos direitos fundamentais e o da subsidiariedade - dependerá do grau de aproximacão e de homogeneidade entre as reivindicações da sociedade e a atuação administrativa, ou seja, em última análise: a legitimidade da ação do poder público.

A solução da democracia indireta, em que representantes eleitos poderiam decidir sobre todas e quaisquer políticas públicas, salvo as que tivessem sido constitucionalmente definidas, é falha, porque parte de uma presunção de legitimidade, mas a evolução em curso para uma democracia direta ou semi-direta. conforme a hipótese decisória de que se cogite, passa a depender da participação cidadã, aberta, assegurada e incentivada pelo Estado.

A doutrina italiana, por certo pelo pioneirismo da inserção constitucional explícita do princípio da participação, ${ }^{8}$ tem tratado o tema da legitimação extra-representativa como uma nuova democraticità, que se caracteriza pela legitimação imediata, contemporânea à administração, e pela criação de uma nova categoria de fontes normativas de aplicação administrativa; um fenômeno ainda em aperfeiçoamento e que, por isso, se ressente de difícil sistematização sob critérios positivistas clássicos ainda cabalmente superados e, também, por esse motivo, de difícil hierarquização nos esquemas rigorosamente kelsenianos.

Nessas condições, o procedimento passa a ser, por via de regra, a nova e dinâmica forma de dar legitimação democrática imediata à ação administrativa, sem intermediação política ou com um mínimo indispensável de atuação dos órgãos legislativos, e, do mesmo modo, através do procedimento, a abertura à participação de interessados, conduzindo à tomada de decisões não apenas as casuístias, mas as 
gerais e, nesta hipótese, com a produção de regras igualadoras com aplicação a todos os que se encontrem nas mesmas circunstâncias reguladas. ${ }^{9}$

\subsection{A contribuição do conceito de Constituição como ordem de valores e a estrutura jurídica das novas relações entre sociedade e Estado}

Um dos grandes avanços do constitucionalismo do Segundo Pós-Guerra, consolidando alguns dos vetores apresentados e tantos outros mais, de magna importância na estruturação do Direito Público contemporâneo, foi a reintrodução de uma ordem de valores como alicerce constitucional.

Essa revolução metodológica, apoiou-se em notáveis subsídios doutrinários, como, desde logo, os lançados por Karl Larenz ${ }^{10}$ em 1960, tempo em que ensinava na respeitável Universidade de Munique, para não deixar de destacar este extraordinário mestre de gerações. Não obstante criticada pela abertura a referências metafísicas, foi essa a necessária ruptura com uma metodologia fria e anquilosada, mas sobretudo descomprometida com a legitimidade, que permitiu, em seus desdobramentos dogmáticos subseqüentes, que se alcançasse o conceito, hoje reconhecido como mais adequado e difundido, de repositório ordenado de valores fundamentais (Grundwerte) o que, para alguns autores, já estaria até em simultâneo processo de universalização e de "personalização" para tornar-se fundamentalmente um repositório ordenado de direitos fundamentais (Grundrechte)."

Está claro que essa reavaliação do constitucionalismo não só elevou a importância dos princípios, que até então eram tidos pelo positivismo jurídico apenas como um grau mais elevado de generalização das regras, ao patamar de uma categoria normativa autônoma e dotada de um sistema de eficácia próprio, como possibilitou que o Direito Constitucional contemporâneo conquistasse novos e elevados parâmetros de efetividade. ${ }^{12}$

Essa ordem constitucional dilargada e travejada sobre valores, com suas lídimas expressões jurídicas, que são os princípios, teve o mérito de incorporar o direito Administrativo e, por assim dizer, o constitucionalizar, com imensa vantagem para o cidadão e para o conjunto da sociedade, pois esse upgrading, elevando à máxima

9 No mesmo sentido, versando esses dois tópicos - procedimento e participação - como momento de legitimação da administração pública, o recente e bem travejado trabalho de IGNAZIO MARIA MARINO, Aspetti della Recente Evoluzione del Diritto degli Enti Locali. Palermo, Ed. Quattrosoli, 2002, p. 91 e ss.

10 Methodenlehre, Berlin-Heidelberg, Springer-Verlag, 1960.

11 JOÃO CARLOS SIMÕES GONÇALVES LOUREIRO, O Procedimento Administrativo entre a Eficiência e a Garantia dos Particulares, Coimbra, Coimbra Editora, 1995, ps. 163 e 164.

12 Para exame detalhado do fenômeno da busca da efetividade constitucional, a monografia, já clássica, de LUIS ROBERTO BARROSO, Interpretação e Aplicação da Constituição, Rio de Janeiro, Renovar, 2001, $4^{\text {a }}$ edição, e para aprofundamento, todo o item 7, do Cap. II, da Parte II desta obra. 
hierarquia normativa a proteção de seus direitos, inibiria que a legislação ordinária introduzisse exceções que não estivessem previstas na Carta Política. ${ }^{13}$

A reestruturação do Direito Público e, especialmente, do Direito Administrativo teria ainda mais uma importante consequência com o travejamento constitucional da legitimidade e da licitude (moralidade): uma abertura enriquecedora possibilitada a partir da ideação do direito como um sistema normativamente fechado mas cognitivamente aberto e, por isso, apto a receber os conceitos provenientes de outros ramos do saber e, assim, a renovar-se permanentemente, afastando o "aspectro de sua degenerescência" 14 .

Em suma, o constitucionalismo contemporâneo não invade a áea da filosofia dos valores, como alegam seus críticos, mas, ao contrário, ampliou-se suficientemente a ponto de permitir que valores sociais, econômicos e culturais, em geral. passassem a ser autopoieticamente absorvidos na ordem constitucional, do que resulta uma nova e sempre renovável feição nas relações entre sociedade e Estado.

\section{A redefinição teórica do interesse público no estado democrático de direito}

\subsection{O conceito de interesse público passa de obstáculo a aspecto essencial da administração pública por consenso}

A vinculação ao interesse público, mais do que uma noção orientadora de uma das modalidades de atuação do Poder Público no cumprimento de sua destinação administrativa, consolidou-se, ao longo de dois séculos, como um dogma, capaz de inibir não apenas a possibilidade de controle do mérito administrativo ante sua invocação peremptória, como de constituir-se em um intransponível obstáculo à admissibilidade de qualquer negociação entre Poder Público e cidadãos em instância administrativa sobre a melhor maneira de realizar-se o seu atendimento. Vencida a primeira barreira, posta ao controle, no século vinte, toca ao século atual superar a segunda.

Ocorre que essa superação já vinha de há muito desenhada no âmbito pactual relativamente à admissibilidade da figura do contrato de direito público, tema de que se ocupou, entre outros, até os clássicos Vittorio Emmanuele Orlando, em 1908, ${ }^{15}$ e Francesco Carnelutti, em $1929^{16}$, que reconheciam que haveria necessariamente uma adaptação (Orlando) e uma transformação de sua natureza (Carnelutti).

13 UMBERTO ALLEGRETTI di-lo bem: "il rapporto Costituzione-amministrazione è bitunívoco in fatto, ma nell'ordine dei valori - che è l'ordine del diritto! - è l'amministrazione che deve conformarsi ai principi costituzionali e non può essere il quadro costituzionali a piegarsi al modo di essere dell 'amministrazione." (Amministrazione Pubblica e Costituzione, Milão. CEDAM, 1996. ps. $10 \mathrm{e} 11$.

14 NIKLAS LUHMANN, apud JOÃO CARLOS SIMÕES GONÇALVES LOUREIRO, op. cit., ps. 173 e 174.

15 Principii di Diritto Amministrativo, Firenze, 1908 (p. 98 e ss.).

16 Contratto e diritto pubblico, artigo in Rivista di Diritto Pubblico, 1929, ps. 659 e ss. 
Coube, todavia, à doutrina alemã a superação do problema da compatibilização entre a definição do interesse público e o exercício da administração consensualizada com a chamada teoria do duplo grau, partindo da distinção entre categorias ou níveis de exercício do poder: a categoria primária (primäre Stufe) e a categoria secundária (sekundäre Stufe), cabendo à esfera do público a decisão primária de poder. que se compreende em sua competência de agir, e à esfera do privado, a decisão secundária de poder, perfeitamente negociável, de escolher a melhor solução para atuar.

Essa solução, que na doutrina italiana prosperou com a denominação de teoria del doppio grado, é a que hoje mais se afeiçoa à visão subsidiária e pluralista do Estado, uma vez que distingue o nível de manifestação de vontade administrativa dotada de um poder estatal primário e, por isso, absoluto, inegociável e inflexível, de dar-se a execução de um determinado interesse público concreto, situada no plano supraordinado das decisões vinculadas, no nível de manifestação de vontade administrativa dotada de um poder estatal secundário e, por isso, relativo, negociável e flexível, situado em plano subordinado das decisões discricionárias.

Um último passo restaria a ser dado, desta feita em sede positiva, ainda na Alemanha, em 1976, com sua Lei geral sobre processo administrativo (parágrafo 54), admitindo que o contrato de direito público possa constituir, modificar ou extingir uma relação de direito público salvo se existir expressa prescrição jurídica em contrário, prescrevendo-se, tanto para o ato quanto para o pacto, indistintamente, a processualização de ambas as categorias de decisões (parágrafo 9).

Mas, sem dúvida, a admissibilidade do consenso administrativo em decisões outrora puramente reservadas às decisões de império, só adviria com a redefinição do conceito de interesse público e a diferenciação entre os tipos de atuação sujeitas à imperatividade administrativa e as sujeitas à autonomia administrativa.

\subsection{Histórico da redefinição: o conceito de interesse público antes do Estado de Direito, no Estado de Direito e no Estado Democrático de Direito. Graus de comprometimento da ação do Estado com a vontade da sociedade}

Como a administração pública e seu Direito gravitam em torno do conceito de interesse público, passou a ser necessário examinar como este conceito variou historicamente sob os influxos das grandes mudanças juspolíticas ocorridas nos últimos duzentos anos.

O ancien régime, com restritas exceções, confundia o interesse do rei com o interesse público: o poder de império não se cindia, não se podendo falar de um conceito dogmaticamente autônomo de interesse público. Com a Revolução Francesa e depois, com o desenvolvimento do positivismo jurídico, o conceito ganhou autonomia, contendo-se nas definições legislativas ordinárias que o definissem, uma vez que, sob a concepção então vigente, não se reconheceria eficácia imediata às definições constitucionais.

Assim, como prevalecia, no Estado de Direito, o caráter meramente programático dos cometimentos constitucionais administrativos ao Estado, restava exclusiva- 
mente ao legislador ordinário a tarefa de torná-los eficazes a partir da especificação que como e quando the parecesse conveniente e oportuno fazer em lei.

Com a evolução do constitucionalismo pós-positivista, ao afirmar, como já se aludiu, a regra da eficácia geral dos comandos constitucionais, notadamente daqueles relativos aos direitos e liberdades e às prerrogativas inerentes à nacionalidade, à soberania e à cidadania, deslocou-se para a sede constitucional a dicção fundamental do interesse público, remanescendo ao legislador ordinário dos três níveis federativos, conforme sua respectiva competência, a tarefa de especificá-los. ${ }^{17}$

Desse modo, apenas excepcionalmente algum interesse público que haja sido consignado genericamente na Constituição carecerá de eficácia imediata, demandando, então, para caracteriar essa excepcionalidade, o emprego da cláusula de reserva legalde eficácia, devolvendo-se à normatividade infraconstitucional a regulação da matéria.

À luz dessas observações, não cabe ao legislador restringir o elenco de interesses públicos que devam ser atendidos pela Administração Pública como, tampouco, pode o administrador omitir-se no atendimento possível daqueles cometimentos. Atentese, todavia, que por atendimento possivel há de se entender o que se conforme à realidade e o que obedeça a prioridades expressas ou implicitamente consignadas na própria Constituição.

Destarte, para ilustrar com um exemplo, o direito fundamental à saúde (aret. $6^{\circ}$ da Constituição) é alçado a interesse público relevante, como tal expressamente garantido na mesma Carta, de modo a que venha a ser atendido em caráter universal e igualitário (arts. 196 e 197), impondo-se tais comandos supraordinados tanto ao legislador quanto ao administrador, de sorte que nenhum deles poderá eximir-se de efetivá-los in concretu (art. 198 da Constituição).

Da mesma forma, para acrescentar-se ainda mais o exemplo da hierarquização de interesses públicos, assim constitucionalizada com o objeto de não se permitir ao legislador ou ao administrador substituir, minimizar ou procrastinar seu atendimento administrativo, tome-se a educação, que é também um direito fundamental (art. $6^{\circ}$ da Constituição) e que será atendido por ações devidas pelo Estado (o "dever do Estado", referido no art. 196).

Esse dever do Estado, ou seja, esse dever de atender a interesse puiblico qualificado e hierarquizado a seu cargo, deverá ser efetivado mediante um elenco de garantias irredutiveis e supraordinadas (art. 208, da Constituição).

\subsection{O interesse público no constitucionalismo de resultado: da eficácia à efetividade}

Como se pode observar, conjugando agora as observações sobre efetividade com o novo conceito constitucional de interesse público, chega-se hoje ao conceito de constitucionalismo de resultado, que tornou obsoleto o de constitucionalismo programático, um fenômeno de tal transcendência que, na expressão de Luís Roberto 
Barroso passou a ser por isso considerado como "a mais notável preocupação do constitucionalismo dos últimos tempos". ${ }^{18}$

Também observável e de modo muito especial, nesse processo de definição jurídica do interesse público sobressai a introdução do resultado da ação administrativa como parte essencial do conceito de finalidade pública e, nele, a evolução da eficácia à eficiência e, desta, à efetividade.

$\mathrm{Na}$ dogmática clássica, a característica jurídica de eficácia dos atos do Poder Público não continha em si qualquer apreciação quanto ao resultado concreto da ação mas, apenas, a de sua aptidão para produzi-lo em abstrato. É evidente que tal caracerística, tão importante quanto as de existência e da validade, que logicamente a precedem, é insuficiente para a adequada descrição desses atos no atual contexto de um Direito ampliado por uma juridicidade de três dimensões: legalidade, legitimidade e licitude.

Realmente, ao se considerar a importância de se aferir o resultado da ação estatal, notadamente na administração pública, torna-se imprescindível aditar a característica finalística da eficiência. Neste sentido, já em 1948, a Constituição italiana, a pioneira Carta Política européia moderna do Segundo Pós-guerra, seguindo os passos de uma doutrina que remontava às lições de Raffaele Resta, incluía em seu texto a garantia do bom andamento da administração com vistas à efetiva realização do conceito de buona amministrazione, ${ }^{19}$ um conceito que trinta anos mais tarde a Constituição da Espanha viria a aperfeiçoar, incluindo-o entre os princípios regedores da pública administração, com a atual denominação de princípio da eficiência. ${ }^{20}$

Nossa Constituição, na mesma linha, registra este princípio entre os cinco que optou por expressar como aqueles que deveriam ser especialmente orientadores da ação administrativa de todos os Poderes, inclusive, por óbvia extensão, a dos órgãos constitucionalmente autônomos, em todos os níveis federativos. ${ }^{21}$

Restava, porém, mais um passo, com a introdução do conceito de efetividade, ou seja, do atingimento satisfativo geral do interesse público. A destacada consequiência dessa despertada preocupação, não apenas com o processo de decisão, como era da tradição administrativa, mas, ainda além, com o resultado do decidido, pode ser bem apreciada na evolução da técnica do controle, pois além dos tradicionais controles de existência, de validade, de eficácia e de eficiêciados atos públicos, acrescentou-se um quinto, o de efetividade, destinado a verificar se a ordem dos fatos reproduz, enfim, a contento, o que foi disposto na ordem jurídica.

Frise-se, portanto, que é este quinto modo de controle ganha especial relevância para a valorização da cidadania, pois é através dele que a legitimidade ganha

18 LUÍS ROBERTO BARROSO, Interpretação e Aplicação da Constituição, Rio de Janeiro, Renovar, 2001, $4^{\mathbf{2}}$ edição, p. 240. Para aprofundamento no tema da efetividade, todo o item 7, do Cap. II, da Parte II dessa obra.

19 Constituição da Itália, art. 266.-2.

20 Constituição da Espanha, art. 103.-1.

21 Constituição do Brasil, art. 37, caput. 
visibilidade na ação do Estado, sendo precisamente essa qualidade que permite confrontar a ação administrativa com o seu resultado prático, ou seja, a verificação finalística daquilo que de modo tão nítido se averba na Constituição Portuguesa: " $A$ Administração Pública persegue o interesse público, no respeito dos direitos e interesses legalmente protegidos do cidadão."22

3.3. Reavaliação das relações sob os critérios postos pelos direitos fundamentais e pelos instrumentos da participação processualizada. Da relação de supremacia à relação de ponderação

Um outro aspecto merece menção nesse ligeiro inventário das mutações constitucionais introduzidas pelos vetores considerados, bem como por outros mais, que a preocupação de brevidade aconselha a não examinar neste ensaio: trata-se do impacto dos direitos fundamentais e da participação sobre o conceito tradicional de relação de supremacia.

Desde logo, a supremacia não seria do Estado, uma vez que a prelazia de um instrumento não poderia sacrificar a substância de um direito fundamental. Tampouco seria uma supremacia, por definição, do interesse público in genere sobre quaisquer outros, ${ }^{23}$ pois os direitos fundamentais, por serem conaturais ao homem e às suas intangíveis personalidade e dignidade, precedem a quaisquer outros, só admitindo aplicação ponderada: a que maximize o atendimento de todos os interesses em conflito.

A passagem de uma viciosa relação de supremacia a uma virtuosa relação de ponderação marca, assim, o atual estádio evolutivo dessa interação, cada vez mais intensa, entre sociedade e Estado e põe em evidência a missão instrumental que the cabe, tudo para que jamais e a qualquer pretexto se volte a invocar supremacias téticas ou raisons d'État para sobrepor quaisquer interesses aos direitos fundamentais.

4. A participação pública no estado democrático de direito: a eficiência como fim e o processo como meio

4.1. Ainda a participação. Atuação impulsionadora da ação do Estado (escolha democrática de opções políticas) maximizadora da ação do Estado (exigência democrática finalística da eficiência)

A intensificação da participação e a multiplicação das figuras consensuais de administração devem ser consideradas como um reflexo da crescente imbricação

22 Constituição de Portugal, art. 266.-1.

23 Le figure convenzionale sono cosi un riflesso del crescente fenomeno del intreccio tra interesse pubblico e istanze private, che è necessario portare alla luce anche nella prospectiva dela difesa del 'pubblico', superando la finzione rappresentata dalla affirmazione dell'esistenza di un interesse pubblico astratto e del tutto avulso - ed al riparo - da interessi differenti" (FRABIZZIO FRACCHIA, L'Accordo Sostitutivo, Milāo, Cedam, 1998, p. 10). 
entre interesses de todo o gênero nas sociedades contemporâneas, o que cria espaços comuns entre o público e o privado, em que se inserem interesses individuais, individuais homogêneos, coletivos e difusos, o que de forma alguma minimiza ou estreita o espaço do público senão que o valoriza, por ampliar-lhe a prossecução, o fomento e a defesa, pela mobilização não apenas da vontade e dos meios do Estado mas os de toda a sociedade convergente.

Seria, portanto, de se esperar que se multiplicassem as modalidades participativas, o que já exige um esforço classificatório específico. Assim, entre os vários critérios classificatórios disponíveis das modalidades de participação (subjetivo, finalístico, formalístico, conteudístico, objetivo e funcional), ${ }^{24}$ o que parte do conteúdo da participação se mostra especialmente adequado para distinguir, como se pretende, os níveis de intensidade da contribuição direta ou semi-direta das pessoas na autação dos entes e órgãos do Estado e, dentre eles, encontrando-se, como forma mais acabadas aquelas em que se transfere aos particulares a co-responsabilidade e até, em alguns casos, a total responsabilidade nas decisões sobre políticas públicas.

Interessam, no momento, os tipos de participação conteudística que promovam a adoção de políticas públicas era desejadas pela sociedade: uma atação impulsionadora da ação do Estado, ou seja, um fomento ao revés.

A devolução aos cidadãos e aos grupos sociais diversos a iniciativa de leis é um tipo já consagrado da modalidade, embora escassamente utilizado no Brasil.

Não é, contudo, necessário que a sociedade organizada eleve às câmaras legislativas, e, em nosso caso, dos três níveis federativos, projetos de lei para este efeito, pois existem disponíveis outras vias politicamente sedutoras para atrair agentes públicos interessados em renovar as fontes legitimatórias de sua atuação.

Como se pode facilmente deduzir, é possível desenvolver inúmeros tipos de participação de conteúdo que não apenas revelem ou ascendam as reivindicações populares como ainda concorram para dinamizar a própria democracia representativa no sentido de torná-la mais eficiente em termos de resultados. ${ }^{25}$

24 As descrições desses critérios e as classificações resultantes podem ser encontradas em nosso Direito da Participação Política - Fundamentos e Técnicas Constitucionais da Democracia, Rio de Janeiro, Editora Renovar, 1992.

25 JUAN JOSÉ LAVILLA RUBIRA alinha a melhora da qualidade da norma entre os fundamentos materiais da participação, ao lado da proteção dos interesses particulares potencialmente afetados e da não menos importante legitimação democrática da norma (La Participación Pública en el Procedimiento de Elaboración de los Reglamentos en los Estados Unidos de América, Madri, Universidade Complutense, Ed. Civitas, 1991, ps. 98 e 111), um livro que ostenta em seu Prólogo, de autoria de EDUARDO GARCÍA DE ENTERRÍA, um notável depoimento sobre o desenvolvimento da "rica casuística jurisprudencial e doutrinária que suscitou o processo de elaboração de Regulamentos estabelecido pela vez primeira pelo Federal Administrative Procedure Act de 1946". do qual derivaram as leis similares de vários países, inclusive a do seu, a Espanha, com sua Ley de Precedimiento Administrativo, de 1958, posteriormente constitucionalizada em 1978 (ps. 21 e 22). 
Embora originariamente, nas sociedades monoclasse e biclasse, tenha bastado uma participação reduzida à escolha de agentes políticos, parece hoje fora de dúvidas que a complexidade dos problemas e das soluções políticas demanda novas formas de participação voltadas à escolha de políticas públicas com grau de diferenciação suficiente para atender às especificidades dos diversos subgrupos sociais reivindicantes. ${ }^{26}$

Esta diferença é sumamente importante para aferir-se não apenas o grau de eficiência juridicamente estimável dessas políticas, como e principalmente, o seu grau de efetividade social.

\subsection{A participação e a processualidade como seu inafastável instrumento democrático.}

Complementa esta achega sobre o conteúdo participativo impulsionador da eficiência da ação do Estado, a exigência de uma forma adequada que possa disciplinar com fidelidade e segurança o processo de formação da vontade participativa, ou seja, a processualidade adequada como instrumento democrático.

Essa processualidade participativa, como qualquer outra que se destine a disciplinar a ação do Estado para conferir-lhe previsibilidade no procedimento e efetiva garantia dos direitos das partes, envolve sempre uma cuidadosa reafirmação do sentido formal do direito ao devido processo, constitucionalmente garantido.

Ainda aqui, a contribuição jurisprudencial e doutrinária dos Estados Unidos da América, berço do moderno direito participativo, é decisiva, ao fundar na cláusula constitucional do due process of law, da Emenda V, o direito de participar em processos regulamentares, abrindo aos sistemas constitucionais de todo o mundo, que explícita ou implicitamente a adotam, não apenas a possibilidade mas o dever de instituir processos participativos adequados para a satisfação do conteúdo formal e material da referida cláusula. ${ }^{27}$

É sobre esses fundamentos material e formal - a busca da eficiência das políticas públicas e o rigor do atendimento da processualdiade - que se vai erguendo a formidável arquitetura juspolítica da nova administração pública, capaz de atender aos desafios institucionais de nosso tempo.

Parece que o êxito e a rebustez dessas teses já estão mais que comprovados pela rapidez e entusiasmo com que os sistemas político-administrativos dos povos à vanguarda do Direito vêm avançando na consensualidade.

26 Sobre este tópico recomenda-se vivamente a leitura do clássico MIGUEL SANCHEZ MORÓN, La Participación del Ciudadano en la Administración Pública, Madri, Centro de Estudios Constitucionales, 1980, que em seu Capítulo I discorre amplamente sobre "as insuficiencias da teoria jusadministrativista clássica ante os câmbios institucionais de nosso tempo".

27 A respeito da evolução jurisprudencial norte-americana, que culminou com a decisão da Suprema Corte no caso Mathews vs. Eldridge (424 U.S. 319, 334-35 (1976), a apreciação de JUÁN JOSÉ LAVILLA RUBIRA, na obra acima citada, ps. 114 a 120. 
5. Expansão da admissibilidade do consenso na administração pública - das modalidades contratuais às não-contratuais

\subsection{O consenso como instrumento de ação estatal. Uma classificação das} modalidades pela natureza jurídica das prestações: o contrato e o acordo

É inegável que o consenso como forma alternativa de ação estatal representada para a Política e para o Direito uma benéfica renovação, pois contribue para aprimorar a governabilidade (eficiência), propicia mais freios contra os abusos (legalidade), garante a atenção de todos os interesses (justiça), proporciona decisão mais sábia e prudente (legitimidade), evitam os desvios morais (licitude), desenvolve a responsabilidade das pessoas (civismo) e torna os comandos estatais mais aceitáveis e facilmente obedecidos (ordem) ${ }^{28}$

Para a ação administrativa em especial, o consenso pode ser adotado não apenas pela via contratual, como tradicionalmente se tem feito, mas pela via do acordo não contratual, ainda incipientemente utilizado no Brasil, pois quase que restrito às duas modalidades mais familiares, a dos convênios e a dos consórcios.

Contratos e acordos, ambos modalidades da figura jurídica do pacto, diferem entre si por várias características, mas aqui interessa sublinhar a que se apoia na natureza das prestações colimadas, pois é nesta que se pode apreciar a diferença entre comutatividade e integração.

Com efeito, enquanto as prestações contratuais são recíprocas, voltadas cada uma delas ao atendimento de interesses distintos dos contratantes, as prestações dos acordos são integrativas, voltadas ao atendimento de interesses comuns.

\subsection{A reduzida admissibilidade histórica do contrato e a expansão de sua admissibilidade como instrumento de ação administrativa pública.}

O corte imperativo, que sempre dominou na administração pública inibia a admissibilidade das modalidades contratuais, embora a História do Direito registre na época das navegações o surgimento de grandes contratos entre a Coroa e os particulares para a exploração das potencialidades econômicas das terras descobertas.

No século dezenove foi a vez das concessões de serviços públicos se desenvolverem e passarem a ocupar um importante nicho na administração pública, que, de outro modo, não teria como realizar os pesados investimentos necessários à expansão dos transportes terrestres e marítimos, das comunicações telegráficas, e dos demais serviços de utilidade pública, reclamados pelas massas populacionais emergentes. 
Por outro lado, a diversificação das necessidades de bens e de equipamentos para a utilização pelo Estado tornava-o cada vez mais dependente da contratação de fornecimento no mercado, ampliando-se, com isso, a prestabilidade das formas contratuais.

Por fim, a carência de recursos fiscais levou as Administrações, para supri-la, à realização de operações de crédito e, com isso, a celebrar contratos com bancos e outras instituições financeiras.

No século vinte, depois de um breve período, coincidente com a eclosão das grandes guerras e das grandes ideologias de massa, a estatização das atividades econômicas reduziu a necessidade das contratações, pois empresas do Estado eram criadas para garantir-lhe o máximo de autonomia econômica.

O término dessa era de confrontações globais coincidiu com a chamada Revolução das Comunicações, despertando os anseios democráticos em sociedades que se tornavam cada vez mais conscientes de seus direitos e da necessidade de reduzir o poder do Estado para torná-lo delas instrumento e não um fim em si mesmo.

O refluxo da economia ao mercado livre e a reposição do Estado da condição instrumental dos interesses legítimos das sociedades reabriram inúmeros canais de relação entre sociedade e Estado e possibilitaram, no processo, o ressurgimento da contratualidade administrativa, tal como hoje se apresenta, notadamente com a transferência de várias atividades, antes conduzidas atipicamente pelo Estado, para a iniciativa privada.

\subsection{A expansão do pacto no Direito Administrativo contemporâneo com a} admissão de vários tipos de acordo como modalidades não-contratuais.

Mas esse aquecimento da ação consensual, que passava a caracterizar, no campo administrativo, o Segundo Pós-Guerra, produziria, além da revitalização das contratações, o surgimento de inúmeros outros tipos de pactos não contratuais entre a Administração e os particulares, bem como entre os próprios entes administrativos públicos, visando à solução de problemas econômicos e sociais de variada índole pela coordenação de vontades e de esforços.

A chamada administração concertada, uma fórmula sintética designativa para "os novos modelos da ação administrativa, ou seja, aqueles módulos organizativos e funcionais caracterizados por uma atividade 'consensual' e 'negocial'",29, em pouco tempo passou a ser empregada não apenas para o desempenho da administração corrente como e principalmente para o desenvolvimento de projetos conjuntos entre a iniciativa privada e as entidades administraivas públicas e até para a solução de conflitos. 
6. Os três gêneros da administração pública consensual: a decisão consensual, a execução consensual e a solução de conflitos consensual

\subsection{Uma classificação das modalidades consensuais da administração concertada segundo a natureza da função e o resultado administrativo visado, face aos interesses públicos a serem promovidos, satisfeitos ou recuperados}

Para adotar uma classificação simples para essas inúmeras modalidades de administração concertada pode-se usar o critério das finalidades administrativas imediatas: a promoção do interesse público, a realização do interesse público ou a recuperação do interesse público. A cada uma dessas finalidades correspondem funções administrativas legalmente postas, bem como modalidades de administração consensual distintas.

A promoção do interesse público se dá pela função decisória administrativa, em abstrato ou em concreto; a função de satisfação do interesse público se dá pela função executiva das decisões abstrata ou concretamente tomadas e a função de recuperação do interesse público, se dá pela função judicativa administrativa, em que se reaprecia da juridicidade das decisões administrativas, das execuções e mesmo das decisões judicativas de que caibam recursos.

São, em suma: a função decisória administrativa abstrata ou concreta, como manifestação de vontade primária da Administração Pública; a função executiva administrativa, como transformação do ato em fato e a função judicativa administrativa, como técnica de superação de conflitos.

Como quaisquer delas admite atuação consensual, tem-se, portanto, respectivamente, um campo de administração decisória concertada, um campo de administração executiva concertada e um campo de administração judicativa concertada.

\subsection{Intensidade da atuação consensual: o consenso como coadjuvante e como determinante da ação administrativa.}

Sob o critério conteudístico, distinguem-se dois graus de atuação consensual, conforme seja a atuação do particular coadjuvante ou determinante em relação à do Poder Público.

A atuação coadjuvante do particular é aquela em que a Administração ouve os particulares e com eles negocia as melhores soluções, mas se reserva a plenitude da decisão. Nesta hipótese, o consenso complementa, coadjuva e orienta a decisão administrativa, sem vincular o Poder Público, que, não obstante, estará obrigado a justificá-la. Será desnecessário que a lei preveja a adoção dessa modalidade, pois não se requer qualquer alteração na competência do órgão decisório.

$\mathrm{Na}$ atuação determinante do particular, distintamente, a Administração deve ouvir os particulares podendo com eles negociar as melhores soluções, em termos de atendimento de todos os interesses juridicamente protegidos envolvidos na relação, mas estará vinculada à decisão que vier a prevalecer, em obediência ao processo adotado. Nesta hipótese, a lei deverá prever que a decisão administrativa será pro- 
duzida pelo consenso, vinculando o Poder Público, pois apenas o legislador pode alterar competências da Administração.

\section{III - GENEROS E ESPÉCIES DE ADMINISTRAÇÃO CONSENSUAL}

7. O consenso na tomada de decisão administrativa - exemplos de espécies: plebiscito, referendo, coleta de opinião, debate público, audiência pública, assessoria externa, cogestão e delegação atípica

\subsection{O consenso como elemento coadjuvante da formação da vontade} administrativa. Exemplos de espécies: coleta de opinião, debate público, audiência pública e assessoria externa.

Em todos esses tipos de institutos consensuais, como se expôs, a Administração deve buscar a audiência dos interessados e, se possível, com eles manter o diálogo e a negociação de interesse, mas somente a ela caberá a decisão, justificando-a de acordo com as achegas recebidas ou refutando-as motivadamente.

Pela coleta de opinião possibilita-se à Administração valer-se dos meios de comunicação em geral para recolher subsídios, em forma de tendências, preferências e de razões, dos segmentos sociais interessados na decisão.

No debate público a participação dos interessados é mais intensa, possibilitando-se à Administração não apenas conhecer as tendências, preferências e razões dos interessados como abrir uma instância de negociação.

$\mathrm{Na}$ audiência pública, como no debate público, amplia-se também a participação dos interessados na decisão, inclusive com instância de negociação, mas, distintamente, se caracteriza por estar submetida a maior formalidade processual podendo servir tanto a uma atuação coadjuvante, a de que aqui se trata, como a uma atuação determinante por parte de interessados regularmente habilitados à participação.

$\mathrm{Na}$ assessoria externa a participação coadjuvante será proporcionada por um ou mais representantes das categorias de interesses que poderão ser atingidos pela decisão. Os assessores externos, que deverão ser nomeados entre pessoas estranhas aos quadros burocráticos da entidade pública a ser assessorada, com ou sem remuneração (múnus público), serão indicados livremente, desde que caracterizada a relação legitimatória do candidato, ou em lista vinculante, devendo, depois de nomeados, serem necessariamente consultados pelo órgão decisório e consignadas as suas contribuições.

7.2. O consenso como elemento determinante da formação da vontade administrativa. Exemplos de espécies: plebiscito, referendo, audiência pública, cogestão e delegação atípica

O plebiscito é uma modalidade constitucional e formal da consulta pública pelo qual o cidadão é convocado a manifestar-se sobre um fato, quase sempre no sentido 
de conferir-lhe ou não valoração jurídica. A Constituição tratou em cinco dispositivos desse instituto participativo destinado à busca de um consenso popular vinculante: em termos genéricos, nos arts. $14, \mathrm{I}, \mathrm{e} 49, \mathrm{XV}$, este para o expresso fim de outorgar ao Congresso Nacional a competência exclusiva para convocar o plebiscito, e para efeitos específicos, nos arts. $18, \S 3^{\circ} ; 18, \S 4^{\circ}$ e no art. $2^{\circ}$ do ADCT.

$\mathrm{O}$ referendo, também um instituto de consulta pública constitucional e formal, destina-se a recolher a manifestação dos cidadãos sobre decisões dos órgãos legislativos e administrativos para que se as mantenham ou se as desconstituam, sendo, assim, uma hipótese rara em que está admitido o exercício da democracia direta, de auto-governo popular, restrita embora aos precisos termos em que se convoca o povo à apreciação de atos praticados. A Constituição previu o instituto no art. 14, II e, no art. $49, \mathrm{XV}$, reservou com exclusividade ao Congresso Nacional a competência para autorizar a realização de referendos.

A audiência pública admite as duas modalidades quanto à vinculação da Administração a seus resultados, mas caberá à lei definir entre uma ou outra ou optar por uma solução compósita. Com efeito, o legislador, tal como se prevê constitucionalmente, salvo cláusula impeditiva expressa, poderá deixar de legislar especificamente sobre quaisquer das matérias de sua competência, optando alternativamente por delas dispor como melhor lhe pareça (art. 48, caput), o que inclui, em geral e a toda evidência, fazê-lo visando à realização de quaisquer modalidades decisórias substitutivas como o são as referendárias, as de consulta pública ou as de deslegalização. ${ }^{30}$

Pela cogestão, o legislador poderá abrir a participaçã̀o na direção de entidades públicas a pessoas qualificadas e para esse propósito especificamente nomeadas. Nesta hipótese, os cogestores nomeadas, normalmente atuando em colegiados, são investidos na competência decisória, no que difere o instituto da aśsessoria externa, acima examinado. A modalidade tem ampla utilização no caso de autarquias e de paraestatais de toda natureza, mas na educação, a cogestão do ensino público tem expressa previsão constitucional (art. 206, VI).

Pela delegação atípica a lei reconhece a eficácia jurídica de atos de colaboração praticadas por entidades privadas. A designação de atípica não explica sua natureza jurídica, que é realmente a de uma técnica de descentralização social. Observe-se que na delegação atípica não há transferência de funções mas o reconhecimento, sob certas condições, de efeitos de interesse público dos atos praticados pelas entidades privadas, como, por exemplo, ocorre com a atuaçãe de associações de moradores, de universidades particulares e de clubes de serviço.

30 Sobre a deslegalização, nosso Direito Regulatório, Rio de Janeiro, Editora Renovar, 2003, Cap. V, 123. 
8. O consenso na execução administrativa - exemplos de espécies: contratos administrativos de parceria e acordos administrativos de coordenação

\subsection{A execução associada com sua caracerística sinérgico-sociopolítica de} potenciar a capacidade de ação do Estado pela composição e pela soma de esforços

A administração dos interesses públicos a cargo do Estado pode ser realizada diretamente - pelos órgãos executivos da União, dos Estados, do Distrito Federal e dos Municípios: - indiretamente - pelos entes públicos por eles criados, como autarquias, paraestatais (integrantes da administração indireta); e associadamente através de pessoas jurídicas de direito privado que se aliam ao Estado sob um vínculo de colaboração de direito público. ${ }^{31}$

A partir da premissa de que o interesse público é próprio do Estado, que deve persegui-lo e realizá-lo na forma da lei e do Direito, mas não é dele exclusivo, pois a sociedade organizada pode e em certos casos deve ter ação concorrente, Abre-se um vasto campo, que a doutrina tem denominado de administração privada associada de interesses públicos.

De modo especial, a execução associada apresenta, entre outras virtudes, uma notável característica sinérgico-sociopolítica de potenciar a capacidade de ação do Estado pela composição e pela soma de esforços entre os setores públicos e privado.

Os vínculos são legalmente definidos de acordo com a natureza das entidades de direito privado associadas, que podem ser, basicamente, entidades paraestatais, que contam com um vínculo de delegação legal, e entidades extraestatais, que se caracterizam pela delegação administrativa; neste caso, contratual, complexa ou unilateral, conforme a natureza do ato instituidor do vínculo. ${ }^{32}$

As paraestatais associadas, embora criadas com personalidade de direito privado, têm situação especial, pois sua colaboração está implicitamente determinada em sua própria criação e por isso não serão tratadas aqui, já que a colaboração das entidades privadas extraestatais é absolutamente voluntária.

Com relação a essas, as entidades extraestatais, a delegação contratual, por sua própria natureza, cria uma relação de sinergia pela composição de meios, instituidora de um vínculo associativo estável, ao passo que a delegação complexa e a delegação unilateral, também por suas respectivas naturezas, criam uma relação de sinergia pela aglutinação de meios, instituidora de vínculos associativos precários.

Essa distinção torna-se necessária para a classificação das espécies contratuais e das espécies não contratuais.

31 Para desenvolvimento dessas figuras, v. nosso Curso de Direito Administrativo. Rio de Janeiro, Editora Forense, 12² edição, 2001, Cap. XI, Entes Administrativos, ps. 235 a 274.

32 Curso de Direito Administrativo, op. cit. p. 259. 


\subsection{A execução associada por contrato e a sinergia da parceria. Espécies de}

contratos administrativos

A modalidade de sinergia contratual, por ser estável, produz uma parceria entre o Poder Público e os entes da sociedade, um tipo de relacionamento que gravita em torno de empreendimentos de substrato econômico.

Outras modalidades de parceria poderão ser também instituídas por atos administrativos, mas, como resulta óbvio, tais relações serão sempre precárias, não se prestando para empreendimentos associativos de natureza econômica de porte, embora sirvam para conciliar o interesse econômico individual de menor monta com o interesse público, durante algum tempo em restritas condições.

As modalidades contratuais de parceria tendem a se multiplicar no Direito Administrativo contemporâneo e isso em razão mesmo da extrema diversidade de situações encontradas na área econômica, como um simples elenco exemplificativo o demonstra: concessões de serviços públicos e de uso de bem público, permissão de serviços públicos, arrendamento portuário, arrendamento operacional, franquia pública, gerenciamento privado de entidade pública, venda de bilheteria e contrato de risco. ${ }^{33}$

Por outro lado, as modalidades unilaterais de parceria, ou seja, as modalidades de administração associada de interesses públicos de conteúdo econômico em parceria por ato unilateral são as seguintes no direito positivo brasileiro: autorização de serviços públicos, autorização portuária, permissão de uso de bem público $e$ credenciamento. ${ }^{34}$

Dada a natureza e o propósito de síntese deste ensaio, dispensa-se de tratar individualmente as modalidades acima referidas, ainda porque estão descritas no livro texto do autor, a que se fez referência.

\subsection{A execução associada não-contratual por coordenação e sua sinergia.}

Modalidades: a cooperação e a colaboração. Execução mista: por cooperação $e$ por colaboração. Exemplos de espécies de acordos administrativos: convênios, acordos de programa, "joint ventures" públicas e conferências de serviços

Distintamente, os entes associados por vínculos não-contratuais buscam coordenar suas atividades de interesse privado com as atividades administrativas de interesse público, identificando pontos de contacto sobre os quais se possa criar uma sinergia relacional que, livremente produzida, poderá do mesmo modo ser extinta a qualquer tempo, enquanto durar o interesse das partes associadas.

Coordenar atividades é maximizar os meios dispostos pelos associados de modo a obter resultados de interesse comum com menos custos e mais celeremente, atuando cada associado em seu específico campo e com seus próprios meios. $\mathrm{O}$ instrumento apropriado para a institucionalizar a coordenação é o ato administrativo complexo. 
A coordenação da atuação da Administração Pública pode dar-se por cooperação ou por colaboração. A cooperação pode ser acordada por consórcios, convênios, acordos de programa ou conferência de serviços celebrados com outras entidades públicas, porque terão todas o dever comum de prossecução do interesse público. A colaboração pode ser ajustada por convênios, acordos de, programa e "joint ventures" públicas celebrados com entidades privadas, neste caso sempre por uma disposição voluntária das associadas.

Nada impede, porém, senão que até se recomenda, que ambas as modalidades de cooperação e de colaboração possam concorrer para um único ajuste complexo, envolvendo acordantes associativos públicos e privados, cada um deles movendo-se em suas respectivas órbitas, com seus próprios cometimentos e recursos, neste caso com o emprego do convênio, do acordo de programa ou de modalidades de "joint ventures" públicas.

9. O consenso na prevenção de conflitos administrativos -- exemplos de espécies: comissões de conflito e acordos substitutivos

\subsection{A prevenção consensual de conflitos e suas características e excelências sócio-políticas. Extensibilidade das soluçōes}

A multiplicação de conflitos entre os sujeitos públicos e privados é um fenômeno que diz respeito à mutação do papel do Estado, que de poder "formalmente impermeável ao impuslo social, idealizado como monolítico e separado dos sujeitos privados destinatários de suas ações, tornou-se progressivamente fragmentário, multiplicando com isso as relações com o resto da sociedade e assim aumentando as ocasiōes de confronto com ela". ${ }^{35}$ Essa fragmentação, por seu turno, é uma inevitável decorrência da nova postura pluralista do Estado - o Estado pluriclasse, na lição de M.S. Giannini ${ }^{36}$ - que reflete a própria realidade pluralista da sociedade contemporânea.

Diante desse fenômeno, causador de uma impressionante avalanche de processos judiciais contra o Poder Público em todos os Países que adotaram as premissas do Estado Democrático de Direito, e que atulha as prateleiras dos órgãos burocráticos com milhares de processos, muitos deles semelhantes quando não repetitivos, conceberam-se institutos em que o consenso pode atuar vantajosamente na prevenção administrativa de conflitos.

35 FABRIZZIO FRACCHIA, L'Accordo Sostitutivo - Studio sul consenso disciplinato dal Diritto amministrativo in funzione sostitutiva respetto agli strumenti unilaterali di esercizio del potere, Milão, Cedam, 1998, p. 2 (n. trad. livre).

36 M. S. GIANNINI, Il pubblico potere, Bolonha, 1986, p. 124 e ss. 
Não seria exagero apontar essas novas vias, não só de atuação preventiva como de composição de conflitos administrativos já instaurados, como importantes conquistas da cidadania e da sociedade, em geral, ora alcançadas graças a essas possibilidades desenvolvidas de utilização do consenso como modalidade substitutiva da ação unilateral e imperativa do Estado.

Essas novas possibildiades são hoje analisadas doutrinariamente sob dois aspectos: de um lado, quanto à substituição da decisão administrativa tradicional (ato administrativo) e de outro, a substituição do processo administrativo imperativo oude parte dele, para incluir procedimentos de contraditório, ampliado ou pelo menos ampliável, e de negociação.

Ressalte-se, por sua modernidade, que uma das características mais auspiciosas encontrada no processo administrativo preventivo de conflitos, bem como no processo de composição administrativa está na extensibilidade potencial das decisões resultantes de acordos dessa natureza a outras situações análogas, ganhando eficácia normativa no âmbito administrativo.

\subsection{Espécies: as comissões de conflito e seu papel antecipatório e regulatório; os acordos substitutivos e sua natureza jurídica.}

Exemplificando com espécies, pode-se destacar dois tipos de processos preventivos, em que procura antecipar a eclosão de um conflito, que se revele iminente, e dar-lhe solução cautelar: a comissão de conflito e o acordo substitutivo.

Instrumentos pouco conhecidos na doutrina pátria, têm ambos, não obstante, um imenso potencial aplicativo, notadamente na administração setorial autônoma, como a praticada no âmbito do Direito Regulatório.

As comissões de conflito são um instrumento administrativo permanente que, de ofício ou por provocação de interessados, detem atuar sempre que se descortinar a possibilidade e iminência de instaurar-se um conflito de interesses no âmbito de sua competência. Sua atuação exige um processo contraditório amplo e aberto a quaisquer interessados, uma vez que a decisão deverá ter latitude suficiente para cobrir as situações análogas porventura existentes, dando-lhes, a todas, tratamento homogêneo, como, por exemplo, através de normas regulatórias específicas, no âmbito das atividades deslegalizadas.

Os acordos substitutivos são instrumentos administrativos, que poderão ser ocasionalmente aplicados pela Administração, sempre que, de ofício ou por provocação de interessado, verificar que uma decisão unilateral de um processo poderá ser vantajosamente substituída por um acordo em que o interesse público, a cargodo Estado, possa ser atendido de modo mais eficiente, mais duradouro, mas célere ou com menores custos.

Como exemplo bem sucedido no direito brasileiro, ainda que insuficientemente processualizado para surtir efeitos com desejável amplitude, mencione-se o ajustamento de conduta, previsto no art. $5^{\circ}, \S 6^{\circ}$, da Lei $n^{\circ} 7.347$, de 24 de julho de 1985 , em dúvida um instrumento já em plena ascenção. 
10. O consenso na composição de conflitos administrativos - exemplos de espécies: conciliação, mediação, arbitragem, ajustes de conduta e similares

\subsection{A composição administrativa consensual de conflitos $e$ suas caracerísticas e excelências sócio-políticas. Extensibilidade das soluções}

As vantagens da composição consensual de conflitos pela via administrativa prescindem de ser aqui tratadas, pois são sobejamente conhecidas, mas a sua importância sócio-política, enquanto via de fomento de civismo, de aperfeiçoamento da participação cívica e de agilização das relações sócio-econômicas, deve ser destacada.

O atraso na aceitação das vias negociais administrativas se deve à visão imperativa, que as considerava interditas para o Direito Administrativo, uma visão herdada da doutrina francesa e bastante arraigada em todos os sistemas que, como o nosso, receberam durante muitos anos sua influência quase hegemônica. ${ }^{37}$

Tecnicamente, afastadas as conviç̧ões ideologizadas pelo tempo e pela inércia, a objeção central se prendia à interpretação do princípio da indisponibilidade do interesse público. Segundo a óptica então dominante, a negociação na esfera administrativa seria negociar com o interesse público, o que proscreveria todos os instrumentos do gênero: a conciliação, a mediação, a arbitragem e os ajustes de conduta.

Ora, distintamente do que se possa aceitar sem maiores indagações, em todas as modalidades preventivas e de composição de conflitos em que se envolva a Administração Pública, no âmbito do Direito Administrativo, jamais se cogita de negociar o interesse público, mas de negociar os modos de atingi-lo com maior eficiência.

É que coexiste, com o interesse público deduzido no conflito, o interesse público, não menos importante, de compô-lo. Esse interesse em dirimir o conflito, e retomar a normalidade nas relações sujeias à disciplina administrativa, é indubitavelmente da maior importância, tanto na esfera social como na econômica, justificando que sejam encontrados modos alternativos de atendimento ao interesse público envolvido, que não aqueles que deveriam ser unilateralmente aplicados pelo poder Público.

Nem é preciso lembrar que em grande número de casos, por inúmeros motivos. principalmente o decurso do tempo, o conflito termina por inviabilizar o atendimento satisfatório do interesse público, quando não exige ônus superiores às vantagens públicas esperadas...

Por outro lado, nem sempre o interesse público deverá preponderar de modo absoluto numa relação, pois outros interesses constitucionalmente protegidos poderão nela concorrer, o que exige soluções ponderadas.

37 Sobre esta dificuldade. a excelente monografia de APOSTOLOS PATRIKIOS, l'Arbitrage en Matière Administrative, Paris, L.G.D.J., 1997, em que o autor estuda a evolução do instituto no Direito francês, possivelmente um dos mais avessos às soluções administrativas negociadas, o que desde logo fica patente na citação de M. DEVOLVÉ: "les rapports entre l'arbitrage et le droit administratif sont de rapports conflictuel" (Nota 1, p. 1). 
Por derradeiro, não se alegue que a imparcialidade, que se requer da administração pública, não se harmonizaria com o emprego de soluções ponderadas; trata-se de um engano corrente, pois imparcialidade não se confunde com neutralidade, de sorte que os valores do Direito não só podem como devem ser aplicados na solução dos conflitos.

\subsection{Espécies: a conciliação, a mediação, a arbitragem, os acordos} substitutivos, os ajustes de conduta etc.

Os institutos da conciliação, da mediação e da arbitragem são três graus em que se apresenta a composição consensual de conflitos: no primeiro instituto, as partes devem, envidar esforços para promover um acordo que ponha fim ao conflito, centrando-se na figura de um conciliador que teria a tarefa de conduzir as partes na negociação e oferecer-lhes alternativas; no segundo instituto, a condução das as negociações por um mediador dar-se-á de modo a reduzir as divergências identificadas e a ampliar as convergências, levantando os inconvenientes de prolongar-se o conflito, de modo a que seja encontrada uma solução satisfatória para as partes: no terceiro instituto, as partes aceitarão a solução do conflito decidida por árbitros. Nas versões administrativas nada impede que o Poder Público possa assumir, agora sim. com a imparcialidade a que está constitucionalmente obrigado, as funções conciliatórias, mediatórias ou arbitrais.

O Direito Administrativo brasileiro, ultrapassando rapidamente as objeções que durante tanto tempo impediam o desenvolvimento das formas alternativas de composição de conflitos, avançou celeremente nessa linha, como o demonstra fartamente a série de legislação produzida na linha do Direito Regulatório a partir de meados da década de noventa. ${ }^{38}$

Essa legislação contempla, quase sempre uma atividade administrativa judicativa para as agências reguladoras, variando, embora, na extensão dessas funções: a Agência Nacional de Energia Elétrica - ANEEL, no art. 3, V. da Lei n 9.427, de 26 de dezembro de 1966; a Agência Nacional de Telecomunicações - ANATEL, no art. 19, XVII, da Lei $\mathrm{n}^{\circ}$ 9.427, de 16 de julho de 1997; a Agência Nacional do Petróleo - ANP, no art. 20, da Lei $n^{\circ}$ 9.478, de 6 de agosto de 1997; a Agência Nacional de Transportes Terrestres - ANTT, no art. 29, II, b, da Lei $n^{\circ} 10.223$, de 6 de junho de 2001 e a Agência Nacional de Transportes Aquaviários - ANTAQ, no art. 20, II, D, da mesma Lei criadora da ANTT. ${ }^{39}$

38 Para maior desenvolvimento do tema, v. n/ Direito Regulatório, Rio de Janeiro, Ed. Renovar, 2003, notadamente os Capítulos V e VIII.

39 az Agências Nacional de Vigilância Sanitária - ANVISA, de Saúde Suplementar - ANS e de Águas - ANA são defectivas quanto a essa função, pois não têm previsão legal para seu exercício. 


\section{Consensualidade enquanto princípio e suas possibilidades}

\subsection{A consensualidade enquanto princípio e sua inferência constitucional}

Este ensaio aponta para a conveniência, senão a necessidade, de desenvolver estudos sobre o princípio constitucional da consensualidade do direito brasileiro. A sua existência terá o condão de iluminar inúmeras relações entre sociedade e Estado e de facilitar, assim, a aplicação e o aperfeiçoamento dos institutos consensuais existentes, a criação de novos e de concorrer para a interpretação homogênea de situações indefinidas.

Para tanto, uma pesquisa nesse sentido poderia partir dos princípios fundamentais constitucionais expressos (Título I), mais especificamente de três dos arrolados no art. $1^{\circ}$ - a cidadania, a dignidade da pessoa humana e o valor da livre iniciativa - sem perder de vista que o homem é a fonte do poder do Estado (parágrafo único), que objetivo fundamental da república é a construção de uma sociedade livre (art. $3^{\circ}$, II) e que se a solução pacífica dos conflitos é um princípio internacional a prevalecer nas relações internacionais, com idêntica razão haverá de sê-lo nas relações intranacionais (art. $4^{\circ}$, VII).

Como se pode prever, só nesses dispositivos há ricos filões a serem garimpados, aos quais se acresce o não menos importante rol dos direitos fundamentais, que está em aberto, pois não exclui outros direitos e garantias decorrentes do regime e dos princípios adotados pela Constituição ou decorrentes dos tratados internacionais de que seja parte o Brasil (art. $5^{\circ}, \S 2^{\circ}$ ).

\subsection{Fomento público, subsidiariedade da coerção e a construção de um Estado de Justiça}

Essas considerações não estariam completas, para os fins deste ensaio, se não invocassem, por derradeiro, a atenção do leitor para a imensa importância da consensualidade no desenvolvimento do modo de atuação mais avançado de que dispõe o Estado: o do fomento.

Pela consensualidade, o Poder Público vai além de estimular a prática de condutas privadas de interesse público, pasando a estimular a criação de soluções privadas de interesse público, concorrendo para enriquecer seus modos e formas de atendimento.

É como acrescentar às potencialidades da máquina burocrática as infinitas potencialidades da sociedade e de suas miríades de organizações sociais, que deixa de ser mera súdita para ser sócia e parceira da atuação estatal, passando a ter no consenso e não na coerção a primeira das opções relacionais.

Em conclusão, um Estado de juridicidade plena - de legalidade, de legitimidade e de licitude - um Estado de Justiça, não pode prescindir dessa interação horizontal e sadia com a sociedade, o que deverá refletir-se em sua atuação, de modo que ações suasórias sempre precedam ações dissuasórias e estas, as sancionatórias: a face imperativa do Poder só deve aparecer quando absolutamente necessário e no que for absolutamente indispensável. A coerção, ensina-nos Pascal, é que domina o mundo, mas é a opinião que a emprega.

Teresópolis, verão de 2003. 